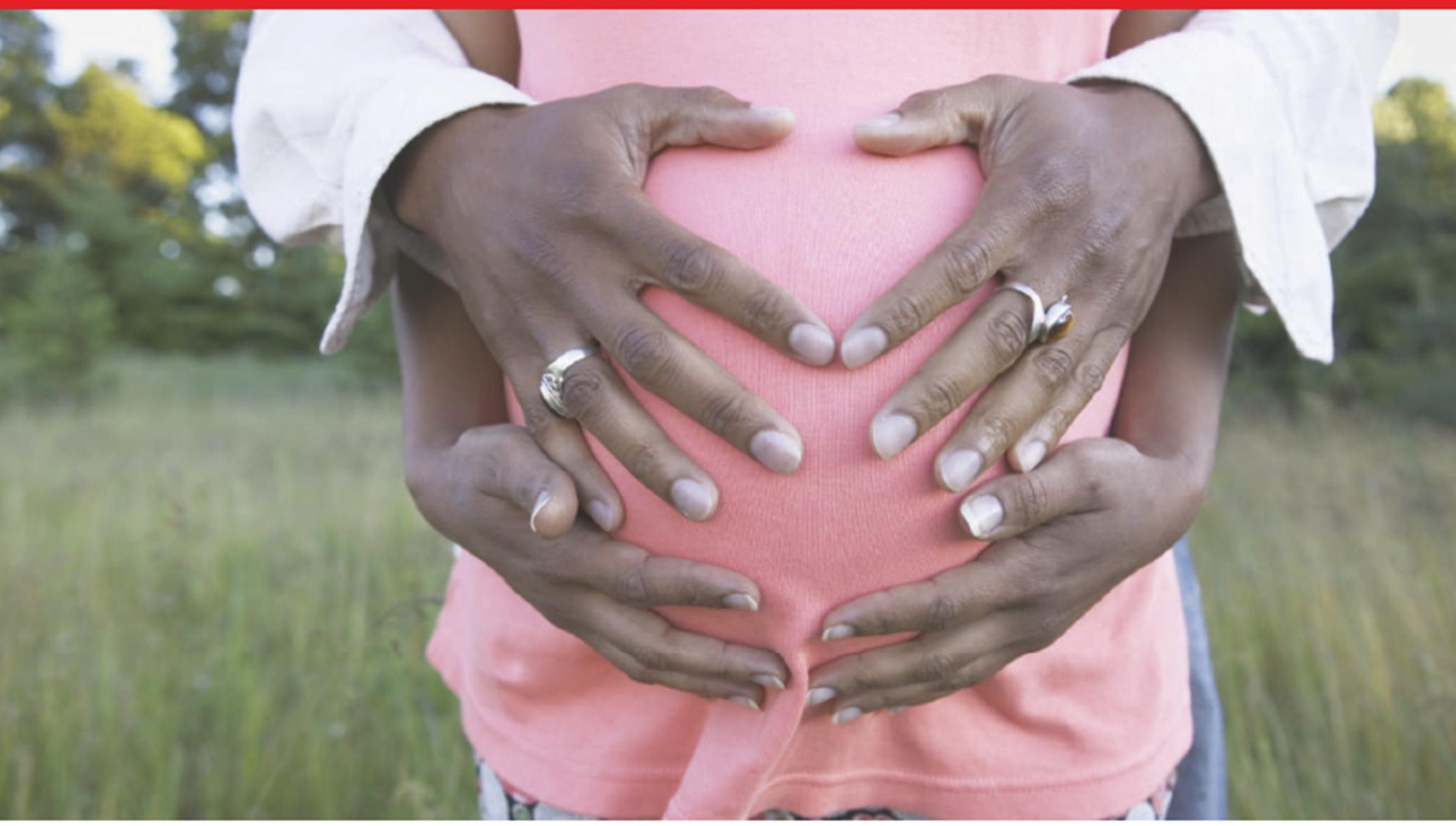

\title{
Fertility on a shoestring
}

\section{IVF isn't something most Westerners associate with Africa. But low-cost methods are urgently needed to treat the misery of infertility rampant on the continent, says Helen Pilcher.}

$\square$ everal years ago, Betty Chishava was thrown out of her family home in Harare, Zimbabwe, because she failed to fall pregnant and didn't want to sleep with her husband's brother. Desperate for an heir and a cure for the stigma of infertility, her husband Herbert took a new wife. Betty was left penniless and alone.

Betty's story is played out in millions of homes across sub-Saharan Africa, where up to one-third of couples are infertile $e^{1}$ and the pressure to produce children is immense. ${ }^{\alpha}$ In Africa, a woman's worth is defined by her fertility, says Chishava. As the years roll by and a couple's lack of children becomes all too apparent, personal tragedies turn into publichumiliation and shame. Perceived as evil or cursed, a woman without a child may be beaten and is commonly ostracized by family and friends. Some risk the threat of HIV to conceive through sex with multiple partners. Some fake pregnancies and steal newborn babies. Some just can't bear it any more and take their own lives.

"If you're a woman in sub-Saharan Africa and you don't have a child, you're worth less than a dog," says fertility specialist Willem Ombelet from the Genk Institute for Fertility Technology in Belgium, who has worked in
Africa for more than two decades.

Treatments for infertility are becoming available in the developing world - but slowly. In 1989 , little more than a decade after the world's first baby conceived through in vitro fertilization (IVF) was born in Britain, western Africa hailed its first IVF success: a boy born at Lagos University Teaching Hospital in Nigeria. Since then a sprinkling of private fertility clinics has sprung up, offering high-tech treatments from the developed world. But the therapy is too expensive for most Africans.

Initiatives are afoot to make fertility treatment more accessible. A number of scientists have proposed methods for developing simpler, low-cost alternatives to the high-tech

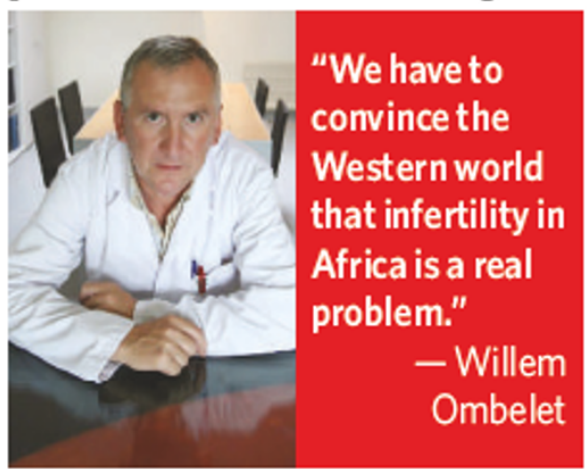

drugs and equipment currently used for fertility treatments. And others are working to prevent the sexually transmitted infections that account for most cases of infertility. But even as campaigners strive to make these approaches a reality, they face daunting prejudice - in both Africa and the wider world.

Perhaps the biggest stumbling block is the insidious conviction (in Western circles) that sub-Saharan Africa simply cannot have an infertility problem. " Governments worldwide put money into family planning in the developing world, but no one wants to focus on infertility," says Ombelet. The average couple in that region has five or six children ${ }^{2}$, so many governments think that being too fertile should be the focus. And they find it hard to justify expensive fertility treatments in settings with few resources that have more obvious problems, such as malaria and HIV. But scientists such as Ombelet insist that the problem needs to be addressed. "Infertility is consistently overlooked in aid and development work," he says. "We have to convince the Western world that infertility in Africa is a real problem."

The sad thing is that much of Africa's infertility could be easily prevented, as infections are the main cause of infertility on the continent. Infections such as gonorrhoea and chlamydia 


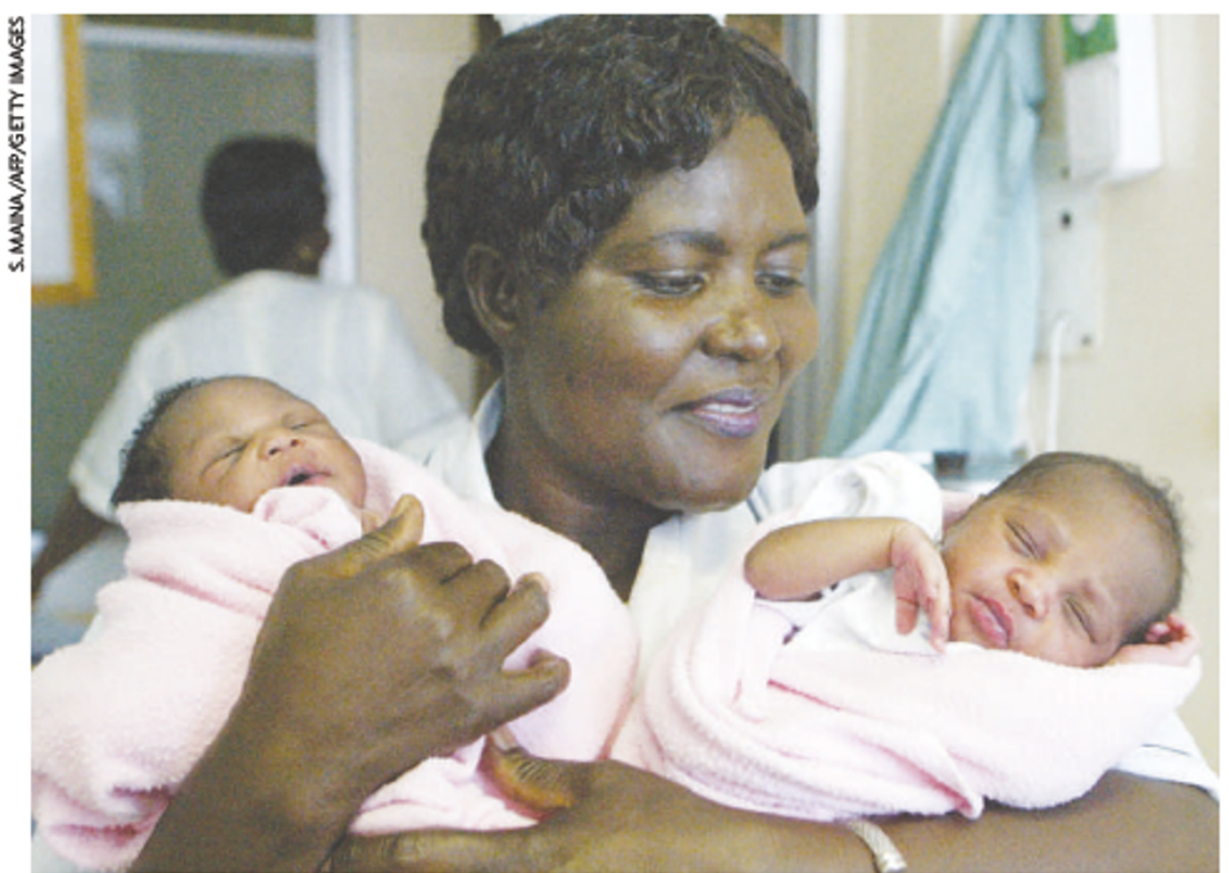

Bundles of joy: Kenya celebrated its first IVF babies last year and clinics are springing up across Africa.

often go untreated, spreading to the reproductive tubes where they cause blockages and scarring. The acceptance of one simple thing - the condom - could change it all.

But cost and cultural taboos restrict condom use. Women, most of whom depend upon men for economic security, find it hard to negotiate safe sex and difficult to refuse intercourse; those who do may risk a beating. Less than $2 \%$ of married women in Africa use condoms ${ }^{3}$.

Bodies such as the World Health Organization have programmes aimed at improving gender equality and the availability of contraception. And results are shortly expected from clinical trials of microbicide gels, which may be effective against a range of sexually transmitted diseases ${ }^{4}$.

\section{Botch jobs}

Meanwhile, the unplanned pregnancies that result from a lack of contraception pose another threat to a woman's fertility. General contraceptive uptake among women remains low, averaging $23 \%$ across sub-Saharan Africa as a whole, reaching just over $50 \%$ in South Africa, and dropping to less than $10 \%$ in Nigeria $^{3}$. All too often, deliveries and abortions turn into botch jobs that cause infection, says obstetrician and gynaecologist Osato Giwa-Osagie from Lagos University Teaching Hospital. He says this is the second biggest factor in the region's female infertility.

Female genital mutilation, which is more common in Africa than anywhere else, carries similar risks. Up to 140 million women have had part or all of their external genitalia removed ${ }^{5}$. The practice is usually performed by traditional doctors with crude instruments and without anaesthetic. Resulting infections can spread internally.

Men, of course, can also be infertile. ${ }^{\alpha}$ But it's always the women who are blamed," says Chishava. Male infertility accounts for up to $40 \%$ of cases of childless couples ${ }^{6}$. Men are usually born with their fertility problems, although infections are also a factor. And yet male infertility is so taboo that no one will admit it exists. Families go to great lengths to cover it up: some resort to the traditional practice of getting a husband's brother to impregnate his wife, something Chishava refused to agree to. Most men in Zimbabwe, and some other countries including Nigeria, would rather change their wife than admit to an infertile marriage, she says.

\section{Cheap tactics}

Changing age-old prejudice is going to take a while. In the meantime, scientists and doctors in Africa and elsewhere are turning to IVF and other fertility treatments to help.

Africa has a more-than-respectable history in assisted reproductive technologies (ARTs). After Nigeria's IVF success in 1989, Giwa-Osagie expected African governments to increase public spending on ARTs. "In terms of technology, we were just a few years behind Britain," he says. But the people with the purse strings prioritized other health concerns, such as malaria and diarrhoea. Africa's public infertility clinics began to feel the pinch and close

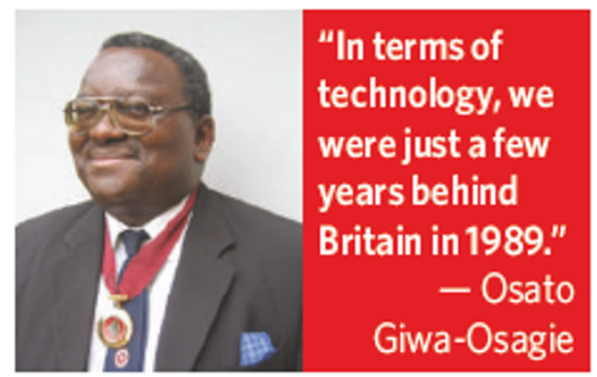

down. "The service became very fragmented and many couples ended up going from doctor to doctor," says Nigerian fertility specialist Richard Ajayi. Those who could afford it, travelled abroad for treatment.

Ajayi and others like him turned to the private sector for funding. Venture capital secured, in 1999 Ajayi founded the Bridge Clinic in Lagos. With its recently founded sister clinic in Port Harcourt, Ajayi's clinics perform more than 500 cycles of IVF treatment a year.

The Bridge Clinic is a polished outfit with state-of-the-art laboratories and new equipment; other places have more humble beginnings. In 2003, gynaecologist Edward Sali set up the Kampala Gynaecology, Fertility and Maternity Centre in Uganda. Funds were tight, so Sali turned his bedroom into the laboratory. "We had to move out," he says.

\section{Clinical excellence}

There are now more than two dozen private fertility dinics scattered across nine or more sub-Saharan African countries. Virtually all forms of ART practised in the West are available, with IVF and artificial insemination by a husband's sperm the most common. Thanks in part to collaboration with sister clinics in the developed world, success rates are approaching those seen in the West. But there's a problem - the cost.

In Nigeria and other countries in sub-Saharan Africa, a single IVF treatment costs around US $\$ 2,500$. But the minimum wage in Nigeria is just US\$52-60 a month ${ }^{6}$ and there are a great many people scraping by on a dollar a day, or less. This makes IVF and other techniques too pricy for most. Ajayi estimates that only 5-10\% of those who could benefit from fertility therapy can afford private treatment.

So what is to be done? Fertility expert Alan Trounson from Monash University in Melbourne, Australia, thinks it's time to go back to basics. He believes that the cost of IVF could be slashed by replacing expensive drugs and high-tech equipment with safe, low-cost alternatives. And he's drawing on experience from veterinary medicine, paediatrics and the early days of IVF to do just that.

Normally when a woman undergoes IVF, she is first injected with hormones called gonadotropins, to help her produce more eggs. Shortly before the eggs are harvested, the woman receives another hormone injection to help the eggs mature. The eggs are then collected using ultrasound guidance, and fertilized in the lab. The work is carried out inside a sterile cabinet called a laminar flow hood, before being transferred to a humidified, gas-filled incubator where the fertilized eggs are left to divide for a few days before being implanted.

"Over the years, IVF has become tailored to treat the Harley Street end of the market," says Trounson. "But there's no reason it can't be tweaked and simplified to create something that is affordable and safe, with a reasonable output." 


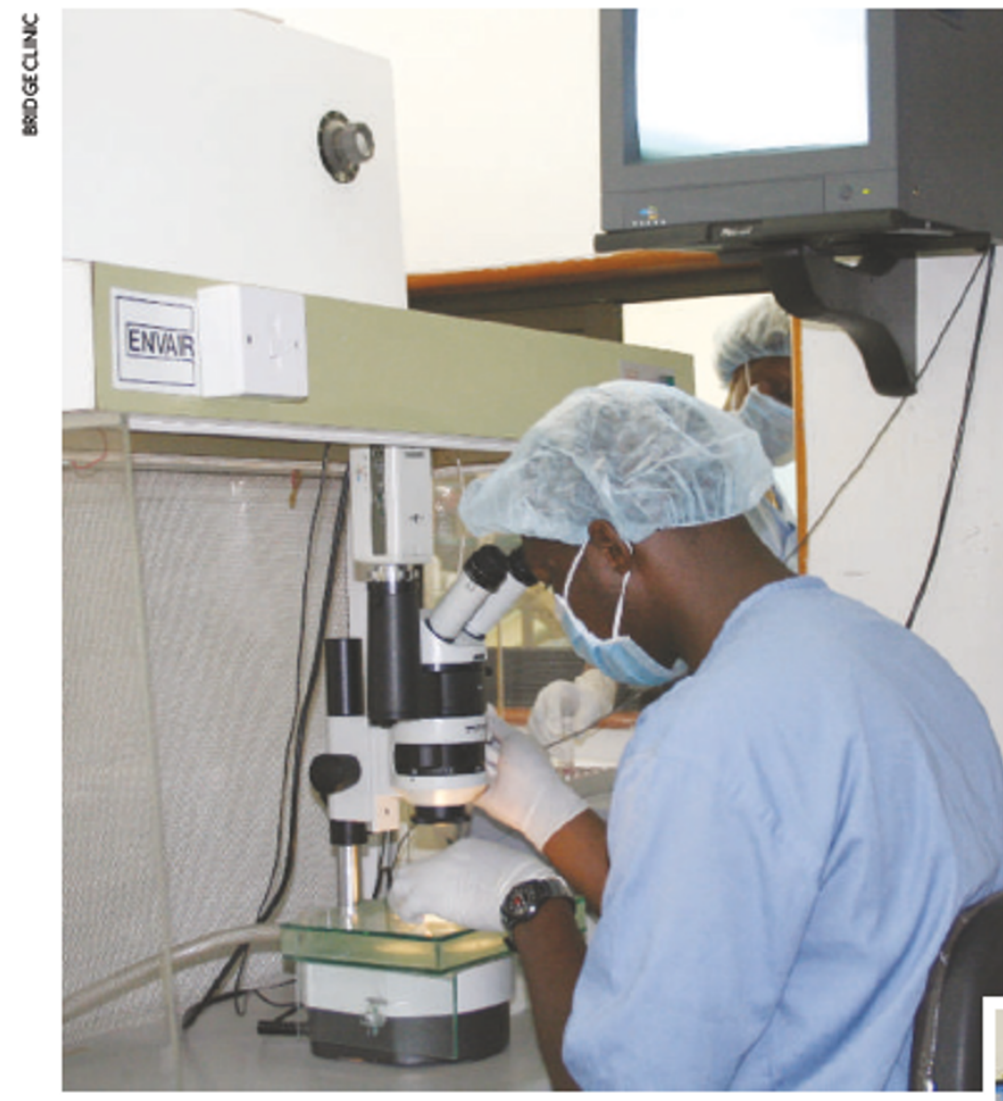

The Bridge Clinic in Lagos uses high-tech tools, but a converted humidicrib (right) also provides a ster ile environment in which to manipulate embryos.

Costly hormone injections could be replaced with cheaper alternatives. Most women use 30 ampoules of gonadotropin per treatment cycle, resulting in about a dozen eggs: the total cost is US\$300-450. But the dose could be reduced or replaced with clomiphene citrate. This drug, which was routinely used in IVF treatments in the late 1960 s, also stimulates ovulation but produces fewer eggs. And 15 tablets cost about US $\$ 1$.

\section{Softly, softly}

Critics of clomiphene citrate caution that it can sometimes damage the uterus lining, making embryo implantation less likely. But advocates say that the 'softer' drug is less likely to trigger ovarian hyperstimulation syndrome, a rare side effect of gonadotropin therapy that can cause diarrhoea, vomiting and breathing difficulties. In the early 1980 s, Trounson managed a roughly $5 \%$ live birth rate using clomiphene citrate, and antenatal care and tissue-culture techniques have come a long way since then. Research is ongoing, but Ombelet estimates that three cycles with clomiphene citrate should be as effective as two cycles with gonadotropins.

Slashing the price of drugs means nothing, however, if doctors cannot afford the equipment needed to fertilize and nurture the eggs. \$ Western IVFlaboratories are replete with technology that costs tens of thousands of dollars, but much of it can be done away with.

In place of the laminar flow hood, Trounson suggests using a 'humidicrib' - a plastic box more commonly used for keeping newborns snug. It's a tenth of the price and can be modified to create a portable, near sterile environment in which to handle embryos.

And instead of incubating the embryos with carbon dioxide from an expensive cylinder, Trounson recommends exhaling across the culture media before sealing it in a plastic bag, a technique commonly used in veterinary IVE. Then remove the need for an incubator by dropping the bag containing the the Petri dish into a warm water bath. Such 'submarine incubators' have been used for cow embryos for more than a decade. " People didn't think to use it in an IVF setting because it's not seen to be sophisticated enough," says Trounson.

Pilot studies are needed to assess the safety and efficacy of such low-cost IVF protocols. Unfortunately, a lack of awareness, cash and political push means this is not happening. So

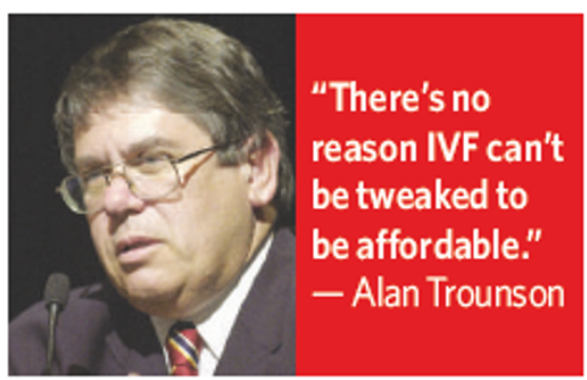

Trounson and others are lobbying hard to put African infertility on the international agenda. Ombelet is organizing a meeting in Arusha, Tanzania, in February 2007, where scientists, clinicians, ethicists, policy-makers and women's organizations will draw up a plan of action. And the Nigerian Fertility Society is drafting guidelines on infertility treatments, which it hopes will be accepted by its government.

As awareness increases, it is hoped that government money will trickle back to fund public infertility dinics. Such low-cost IVF could help millions of women. But government support and publicly funded clinics will mean little if the social stigma is not tackled. "Women have no voice in Africa," says Ombelet, "so raising the status of women may be the hardest job of all.

\section{Home truths}

That's where Chishava comes in. When she was thrown out of her family home, she realized that there was a need for female counselling and education. So six years ago, she set up the Chipo Chedu Society (meaning 'our gift' in her language). The organization aims to help childless women become financially independent, teaching them practical and business skills such as batik and bookkeeping. It puts women in touch with medical experts and fights $<$ prejudice through rural workshops on infertility. The society has more than $\mathbf{5 0 0}$ members and Chishava hopes to see her network spread across Africa.

Chishava has since been reunited with her husband. His second and third marriages failed to produce children, and he gradually accepted that he was infertile. He apologized to Chishava and fully supports her work. Now 54, Betty is mother to five children - all given to her by family members - but she would dearly love to have a child of her own and is intrigued by IVF. Until that happens, Chipo Chedu is her true baby. ${ }^{\alpha}$ I will only find peace of mind when the programme flourishes," says Chishava. "If my neighbour has no children, then their problem is my problem."

Helen Pilcher is a science writer based in Nottinghamshire, UK.

1. Daac, A.S. \& Merali, Z.Infertility and Social Suffering: the Case of ART in Developing Countries (World Health Organization, 2001); ava lable at http///wwwowhoint/ reproductive-health/infertility/5.pdf

2. UNICEF Fer filityand Contraceptive Use (2001); available at http://wwwchildinfo.org/eddb/fertility/index.htm.

4. UN World Contraceptive Use (2003); a vailable at http://wwwun.org/esa/population/publications/ contraceptive2003/wcuR2008.htm

3. Pilcher, H. Nature 430, 138-140 (2004)

5. World Health Organization factsheet 241 (2000); available at http://wwwwhoint/mediacentre/ tactsheets/fs241/en

6. Giwa-Osagie, Q F.ART in Developing Countries with Particular Reference to Sub-Saharan Africa (World Health Organization, 2001); avallable at http//wwwowhoint/ eproductive-health/infertility/6pdf

See also Editorial, page 957. 